\title{
Theorizing and Social Gerontology
}

\author{
BY VERN BENGTSON
}

Theory is increasingly important in social gerontology. Thus it is gratifying to see the debut of a new journal that encourages theorizing about age and aging. The papers in Volume 1, number 1 of the International Journal of Ageing and Later Life reflect a concern for developing theory that is laudable. I hope that in the future researchers who submit manuscripts to IJAL and the reviewers who evaluate them will share this concern for building theory. This is because we are at a tipping point, a watershed, in the development of knowledge about the social and psychological dimensions of aging.

\section{Theorizing as A Mystique}

What is theory? It is simply an attempt to explain what we find out from empirical research.

But there is a mystique about theory. To my $\mathrm{PhD}$ students, theory often seems formidable, a difficult-to-access collation of abstract ideas that cannot be understood without monk-like contemplation of ancient texts. I think it is important to de-mystify theory.

All theory is an attempt, an initial step in the process of developing an account of the how and the why leading to what we have observed in our research. Such attempts are not final solutions. They are rough drafts, to be revised and revised again in the course of our investigations and in response to further empirical research findings. 
Theories involve explanation - or substitute the term understanding if you feel explanation implies too much of a positivistic or scientific paradigm. To me, explanation and understanding are much the same. Each requires an intellectual leap from the content of data collected to the interpretation of what these data mean.

Theory-building is courageous because it requires that we think that we go out on a limb beyond our visible data. Ph.D. programs train very well in technologies, the best ways to collect and analyze data. These lead to the "findings" we report-empirical generalizations or constructs based on Ph.D.-level research. But graduate programs may not prepare us well to jump from empirical generalizations to explanations. This is a courageous leap. It requires thinking, putting ideas together, and creating narratives about what goes with what...

\section{Theorizing as A Process}

I like the term "theorizing" rather than more passive phrases such as "using theory" or "applying theory. I like the focus to be on theory as a verb, rather than a noun or modifier.

Unfortunately "theory" is often associated with some solidified set of ideas, detached from the processes that led up to these ideas; or theory is associating memorizing ideas and names of scholars long dead. One of my students wrote in the evaluation at the end of my theory course that "theory is some arcane body of reasoning associated with a name that you have to memorize in order to appear knowledgeable in this class." No; that is not what I mean by theory.

The process of theorizing begins first with intuition, an awareness of ideas, and the development of hunches about how these ideas are linked. The second step is to formalize these hunches into hypotheses, models, or expectations about what goes with what. Third is empirical researchresearch that allows us to test the hypotheses or the expectations we have about associations. A fourth step in theorizing is revising the model or explanation in light of what we have seen in our empirical study. From these steps, theory emerges as a tool to help us explain, understand, and give meaning to the data we have collected. 


\section{Theorizing as Honest (Explicit)}

I believe that researchers should be explicit in theorizing - that is, they should put in words or symbols the links they believe they have observed between variables or concepts. They should be honest and direct about the linkages they see or feel.

Unfortunately much that has been published in social gerontology to date makes no reference to theory. A review of the literature in social gerontology from 1990 to 1994 revealed that the vast majority $-72 \%$ of all publications in eight journals - made no mention of any theoretical tradition in the literature as relevant to the empirical findings reported (Bengtson, Burgess \& Parrot 1997). The authors caution that "the ad hoc, descriptive, model-based (rather than explanatory or theory-based) approach to research is ineffectual, over time" and that "if authors, journal reviewers, and editors ignore the need for explicit explanation in data analyses, it is not likely that we will achieve much cumulative knowledge development" in social gerontology" (Bengtson et al. 1997: S75).

An unfortunate result is that social gerontology may be accumulating a vast collection of empirically-based generalizations without the parallel development of integrated knowledge. But the development of explanations - theories - is central to both the creation of cumulative knowledge and the application of that knowledge to interventions such as therapy, support, and public policy in aging. For without good explanations about how and why problems arise, it is impossible to develop effective interventions to change them for the better.

\section{Theorizing as A Game}

I like to think of theorizing as putting together a puzzle. The data I collect are pieces of a giant jigsaw puzzle. Each piece by itself is incomplete, meaningless, confusing. But in trying to understand how the pieces fit together I arrive at a larger and more coherent picture.

Theorizing is fun. It is an intellectual game that can be played by everyone involved in gerontological studies, from the neophyte student to the experienced scholar. Fitting the pieces of the puzzle together is fun, though sometimes frustrating, particularly when the overall picture is vague or elusive and often you have to create your own puzzle, instead 
of simply solving one that someone has handed you. This is where the real creativity comes in.

\section{Theorizing as Trying on Lenses}

I am not saying that there is an explanation to be discovered, a reality of causes and effects "out there" that can be uncovered by persistent thinking. This is the stereotypic claim of positivism. But obviously we create theories; we do not discover them.

I think of theories as lenses. We create lenses to better see the world around us. Put on one kind of lens and we can see one object; put on another lens and we can see something different. I believe that social gerontology is a multiple-paradigm field, with several different paradigms and theories operating and changing all the time. It is necessary to try on several lenses in order to see and understand the complexity and diversity of aging.

\section{Promising Prospects for The International Journal of Ageing and Later Life}

Because (from my perspective) explicit theorizing is the best way to build cumulative knowledge, I was very pleased to see the articles in this inaugural number of IJAL. Each reflects, in different ways, the ongoing process of theorizing.

In his article Lars Tornstam de-mystifies "ageism" as a theoretical concept by examining it as a constellation of perspectives. His analysis reflects the process of theorizing, and he is quite explicit (honest) in describing the genesis of his conceptualization. He presents a typology of constructs that are both conceptually novel and can be empirically tested: the consistently negative, the consistently positive, the pitying positive and the "no fuzz."

Liz Schwaiger examines relationships between body and mind (subjectivity) in mid-life. She uses theoretical lenses associated with social constructionist, psychoanalytic, and feminist thought to view a historically contingent and ageist perspective on older age. 
In their article the Bangladesh team of researchers (Biswas, Kabir, Nilsson, and Zaman) provide well-founded empirical generalizations that can be the basis for future theorizing. What can be done to ameliorate the position of elders at need of health care? How and why are current health care systems (familial or governmental) becoming inadequate; and what might alter this-policies and programs to ameliorate these problems?

The Nyqvist, Gustavsson and Gustafson paper examines an important theoretical construct, social capital, and its linkage to several dimensions of health. This is an example of explicit theorizing, and the results suggest that additional theoretical development could lead to more useful intervention strategies.

\section{Conclusion}

I think we are now at a tipping point, a historical watershed, in the historical development of accounts concerning age and ageing. In the past we have amassed an impressive number of empirical generalizations well-conducted research findings - concerning many aspects of social gerontology. But these studies, with their increasingly sophisticated research designs or tools for qualitative analyses, are not enough. In the future we must pay more attention to theory - de-mystified, as a process, being explicit, played as a game, using multiple lenses.

If we focus on theory as an attempt to explain we might be able to provide more useful interventions to improve the quality of life for older people - and for us, their children and the aged of the future.

Bengtson, V.L. Burgess, E.O. \& Parrott, T.M. (1997). Theory, explanation, and the third generation of theoretical development in social gerontology, Journals of Gerontology, B52:S72-S88. 